\title{
Synthesis of Graft Copolymer from Copolymerization of Styrene-terminated Poly(ethylene oxide) Macromonomer and Styrene with $\mathrm{Ni}(\mathrm{acac})_{2} /$ Methylaluminoxane Catalyst
}

\author{
Kiyoshi ENDO ${ }^{\dagger}$ and Tomoaki SUGITA \\ Department of Applied Chemistry, Graduate School of Engineering, Osaka City University, \\ Sugimoto, Sumiyoshi-ku, Osaka 558-8585, Japan
}

(Received June 21, 2004; Accepted September 14, 2004; Published December 15, 2004)

\begin{abstract}
Copolymerization of styrene-terminated poly(ethylene oxide) (PEO) macromonomer (SEOM) and styrene (St) with $\mathrm{Ni}(\mathrm{acac})_{2} / \mathrm{MAO}$ catalyst was investigated. The copolymerization of SEOM and St with the $\mathrm{Ni}(\mathrm{acac})_{2} / \mathrm{MAO}$ catalyst proceeded to give a high molecular weight graft copolymer consisting of hydrophobic styrene units as the main chain and hydrophilic PEO units as the side chains. The numbers of graft chains were controlled by varying SEOM contents in the comonomer feed. The graft copolymer obtained from the copolymerization of SEOM and $\mathrm{St}$ with $\mathrm{Ni}(\mathrm{acac})_{2} / \mathrm{MAO}$ catalyst contained isotactic triad in a lower amount than that of poly(St) obtained with $\mathrm{Ni}(\mathrm{acac})_{2} / \mathrm{MAO}$ catalyst. [DOI 10.1295/polymj.36.949]

KEY WORDS Graft Copolymer / Copolymerization / Ni(acac) $)_{2}$ / MAO / Styrene-terminated Poly(ethylene oxide) Macromonomer / Styrene /
\end{abstract}

Macromonomer technique is a useful and excellent method for preparing graft copolymers with the controlled molecular weight and narrow molecular weight distribution of side chain, when macromonomers synthesized by a living polymerization were used. Graft copolymers consisting of macromonomers and vinyl monomer were prepared mostly by radical copolymerizations. ${ }^{1-8}$ The development of metallocene catalysts makes it possible to synthesize graft copolymers by copolymerization of macromonomers and vinyl monomers or olefins. Such graft copolymers prepared with metallocene/methylaluminoxane (MAO) catalysts have been reported. ${ }^{9-16}$

Among transition metal catalysts, Ni-based catalysts are effective for polymerizations of various kinds of unsaturated monomers. ${ }^{17-27}$ High isotactic poly $(\mathrm{St})$ was synthesized by polymerization of $\mathrm{St}$ with $\mathrm{Ni}(\text { acac })_{2} / \mathrm{MAO}$ catalyst. ${ }^{18}$ Moreover, $\mathrm{Ni}(\mathrm{acac})_{2} /$ MAO catalyst was applied to synthesize an isotactic graft copolymer with controlled side chain length from copolymerization of styrene (St) and styreneterminated poly(isoprene) macromonomer (SIPM). ${ }^{28}$

One of features of metallocence-catalyzed polymerization is tolerance for polar groups containing monomers such as methyl methacrylate and acrylates. Although Ito and his coworkers ${ }^{29-31}$ synthesized the amphiphilic graft copolymer consisting of SEOM and St by a radical copolymerization, copolymerization of SEOM and St with transition metal catalysts was not investigated.

In a previous paper, we synthesized a highly syndiotactic graft copolymer from the copolymerization of SEOM and St with $\mathrm{CpTiCl}_{3} / \mathrm{MAO}$ catalyst. ${ }^{32}$ This suggests that copolymerization of SEOM and St with $\mathrm{Ni}$ (acac) $)_{2} / \mathrm{MAO}$ catalyst is possible to give graft copolymers. In this article, we report on copolymerization of SEOM and St with $\mathrm{Ni}(\mathrm{acac})_{2} / \mathrm{MAO}$ catalyst for a synthesis of graft copolymer consisting of St units as the main chain and PEO units as the side chains.

\section{EXPERIMENTAL}

\section{Materials}

Commercially grade poly(ethylene glycol) monomethyl ether was used without further purification for synthesizing SEOM. St (Wako Pure Chemical Co.) was purified by distillation over calcium hydride before use. Ni(acac) $)_{2}$ (Dojin Chem. Co.) was used after sublimation at about $140{ }^{\circ} \mathrm{C}$ under high vacuum. Sodium hydride and $p$-chloromethyl styrene ( $p$-CMS) (Aldrich Chem. Co.) were used without further purification. SEOM was prepared according to the method by a literature. ${ }^{31}$ The $M_{\mathrm{n}}$ of prepared SEOM was determined to be $2.1 \times 10^{3}$ by vapor pressure osometry, and $\omega$-end functionality of St unit in SEOM was estimated to be 0.97 . MAO diluted with toluene was kindly supplied from Tosoh Chem. Co. and used as received. Solvents and other reagents were purified by conventional methods.

\section{Copolymerization of Styrene and SEOM}

Graft copolymerization of SEOM and St was carried out in a sealed glass tube with rubber stopper with a connection to vacuum system. The required amounts

${ }^{\dagger}$ To whom correspondence should be addressed (Tel: +81-6-6605-2697, Fax: +81-6-6605-2697, E-mail: endo@a-chem.eng.osaka-cu.ac.jp). 
of reagents were charged into the tube by a syringe through a rubber septum under nitrogen atmosphere. After copolymerization, the contents of the tube were poured into a large amount of methanol containing a small amount of hydrochloric acid to precipitate the polymer formed. The resulting polymer was filtered through a glass filter and washed with an excess of methanol, then dried under high vacuum. The yields were calculated from the weight of dry polymers obtained.

\section{Characterization of Polymers}

Polymer structure was checked by the ${ }^{1} \mathrm{H}$ and ${ }^{13} \mathrm{C}$ NMR spectra using a JEOL $\alpha-400$ spectrometer. The NMR spectra of SEOM and graft copolymers were measured in $\mathrm{CD}_{3} \mathrm{OD}$ at $20^{\circ} \mathrm{C}$, and in $o$-dichlorobenzene $/ \mathrm{C}_{6} \mathrm{D}_{6}(50 / 50 \mathrm{wt} \%)$ at $120^{\circ} \mathrm{C}$, respectively. Molecular weight of SEOM was determined by vapor pressure osmometry (VPO) using a Knauer Vapor Pressure Osmometer. Number average molecular weight $\left(M_{\mathrm{n}}\right)$ and the molecular weight distribution $\left(M_{\mathrm{w}} / M_{\mathrm{n}}\right)$ of the graft copolymers were determined by gel permeation chromatography (GPC) using a Waters $\mathrm{GPC} 150 \mathrm{CV}$ in $o$-dichlorobenzene at $120^{\circ} \mathrm{C}$ as calibrated with polystyrene standards.

\section{RESULTS AND DISCUSSION}

\section{Copolymerization of SEOM and St}

Copolymerization of SEOM and St with $\mathrm{Ni}(\mathrm{acac})_{2} /$ MAO catalyst was conducted. Table I list the results of the copolymerization and of the polymerization of St for comparison. The copolymerization of SEOM and $\mathrm{St}$ with the $\mathrm{Ni}(\mathrm{acac})_{2} / \mathrm{MAO}$ catalyst proceeded to give a methanol insoluble product, but the copolymerization rate was slower than polymerization rate of St. ${ }^{17,18}$ Generally, the separation of macrmonomer from copolymerization products after the copolymerization of macromonomers and vinyl monomers is difficult due to similar solubility between macromonomer and the graft copolymers. In the copolymeriza-

Table I. Copolymerization of $\mathrm{SEOM}^{\mathrm{a}}$ and $\mathrm{St}$ with $\mathrm{Ni}(\mathrm{acac})_{2} /$ MAO catalyst in toluene at $0^{\circ} \mathrm{C}$ for $160 \mathrm{~h}^{\mathrm{b}}$

\begin{tabular}{lcccc}
\hline $\begin{array}{c}\text { [SEOM] } \\
(\mathrm{g})\end{array}$ & $\begin{array}{c}\text { Yield } \\
(\%)\end{array}$ & $M_{\mathrm{n}} \times 10^{-4}$ & $M_{\mathrm{w}} / M_{\mathrm{n}}$ & $\begin{array}{c}\text { Number of graft } \\
\text { per chain }^{\mathrm{c}}\end{array}$ \\
\hline 0 & $\sim 100$ & 2.6 & 2.23 & - \\
0.1 & 5.9 & 11.3 & 2.46 & 7.6 \\
0.2 & $6.8^{\mathrm{d}}$ & 9.0 & 2.60 & 13.7 \\
1.0 & 8.2 & 5.9 & 1.97 & 16.6 \\
\hline
\end{tabular}

${ }^{\mathrm{a}} \mathrm{SEOM} ; M_{\mathrm{n}}=2.10 \times 10^{3 \mathrm{~b}}[\mathrm{St}]=2.6 \mathrm{~mol} / \mathrm{L},\left[\mathrm{Ni}(\mathrm{acac})_{2}\right]=$ $6.8 \times 10^{-4} \mathrm{~mol} / \mathrm{L}, \mathrm{MAO} / \mathrm{Ni}=50,{ }^{\mathrm{c}}$ Calculated from ${ }^{1} \mathrm{H}$ NMR spectrum of the copolymer and molecular weight. ${ }^{\mathrm{d}}$ Tacticity of the polymer is as follow; $\mathrm{mm}=25.7 \%, \mathrm{mr}=46.3 \%, \mathrm{rr}=$ $28.0 \%$.

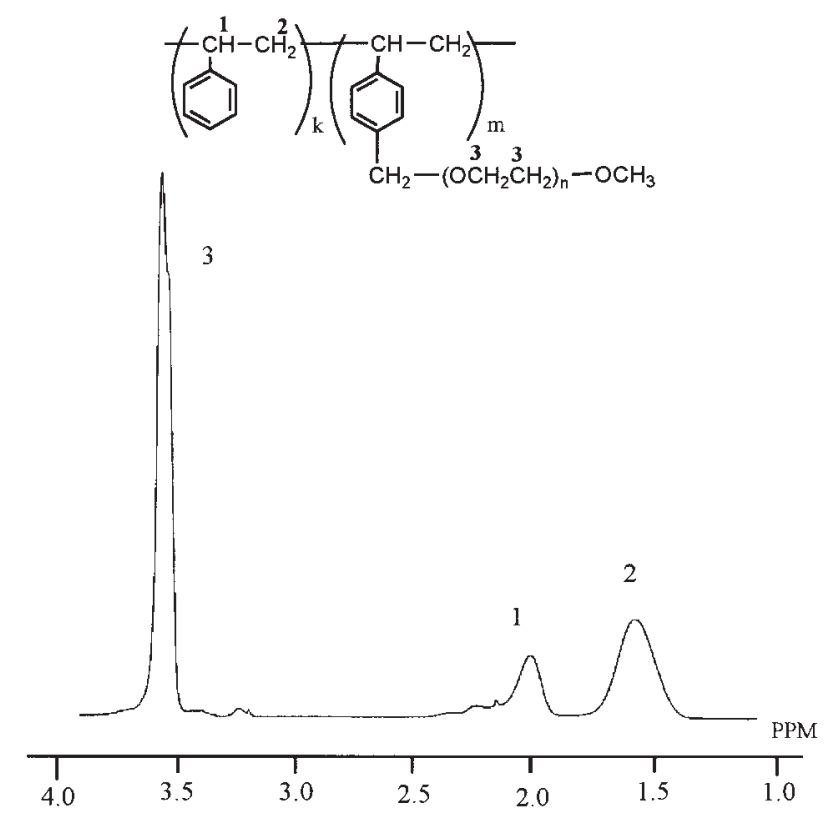

Figure 1. ${ }^{1} \mathrm{H}$ NMR spectra of the polymers obtained from copolymerization of SEOM and $\mathrm{St}$ with $\mathrm{Ni}(\mathrm{acac})_{2} / \mathrm{MAO}$ catalyst measured in $o$-dichlorobenzene $/ \mathrm{C}_{6} \mathrm{D}_{6}$ at $120^{\circ} \mathrm{C}$.

tion of SEOM and St, however, SEOM was easy removed from the copolymerization products by washing them with an excess of methanol, because SEOM is soluble in methanol used as a precipitant. Actually, in the ${ }^{1} \mathrm{H}$ NMR spectrum of the product as shown in Figure 1, the signals based on double bond of SEOM were not observed. In the GPC elution curve of the copolymerization products, no signal which corresponds to the molecular weight of SEOM was observed. Thus, SEOM was confirmed to be removed completely from the copolymerization products by washing them with an excess of methanol. Namely, it is clear that the methanol insoluble fraction is a graft copolymer consisting of SEOM and St.

The copolymer yields increased with an increase of SEOM in the comonomer feed, but the yields were lower than polymerization of St. The GPC elution curve of the graft copolymer obtained from copolymerization of SEOM and $\mathrm{St}$ with the $\mathrm{Ni}(\mathrm{acac})_{2} /$ MAO catalyst showed a unimodal, and the polydispersity $\left(M_{\mathrm{w}} / M_{\mathrm{n}}\right)$ of the reaction product was around 2.0. This suggests that the copolymerization of SEOM and St with the $\mathrm{Ni}(\mathrm{acac})_{2} / \mathrm{MAO}$ catalyst took place with a single site affording a high molecular weight graft copolymer.

\section{Effect of SEOM Concentration}

Because SEOM was found to be incorporated easily into the graft copolymer in the copolymerization of SEOM and St with $\mathrm{Ni}(\mathrm{acac})_{2} / \mathrm{MAO}$ catalyst, the effect of SEOM concentration on the copolymerization of SEOM and St with $\mathrm{Ni}(\mathrm{acac})_{2} / \mathrm{MAO}$ catalyst was 


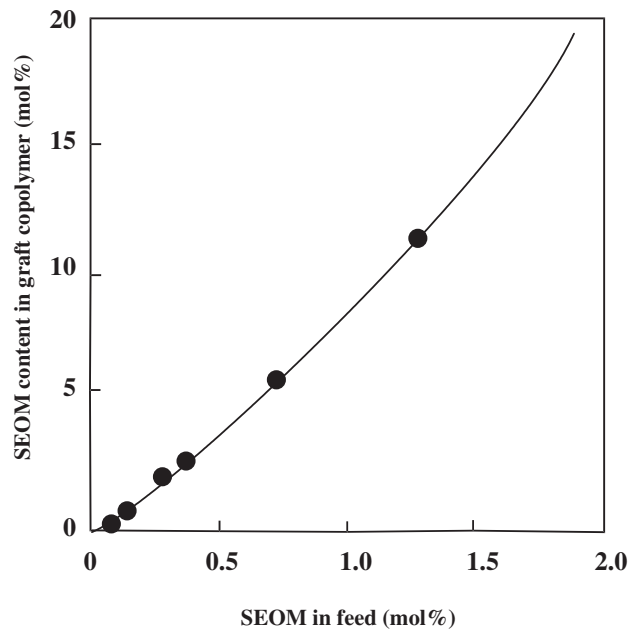

Figure 2. Relationship between SEOM content and SEOM in feed.

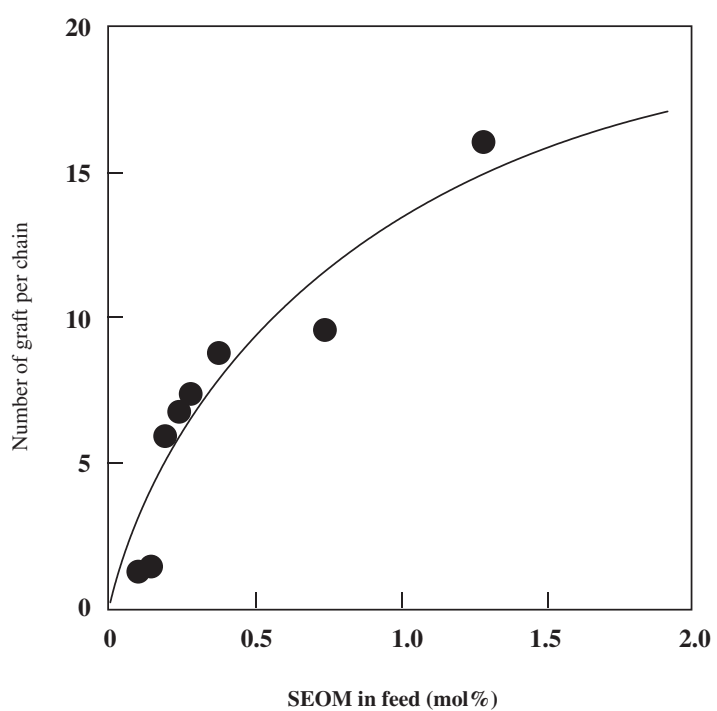

Figure 3. Relationship between Number of graft per chain and SEOM in feed.

examined. The results are shown in Figure 2. Despite that SEOM has a high molecular weight, SEOM content in the graft copolymer increased with an increase of SEOM in the comonomer feed. Moreover, the contents of SEOM in the graft copolymer are higher than that in the feed. This is contrast to that macromonomer was hardly incorporated into the main chain in the copolymerization of SIPM and St with $\mathrm{Ni}(\mathrm{acac})_{2} /$ MAO catalyst. ${ }^{28}$

The relationship between the amount of SEOM in feed and number of graft per molecule is shown in Figure 3. In accordance with the contents of SEOM in the graft copolymer, the number of graft chains per molecule increased with an increase of SEOM in the comonomer feed, indicating that it is possible to control the number of PEO side chain of the graft copolymer obtained from copolymerization of SEOM (a)

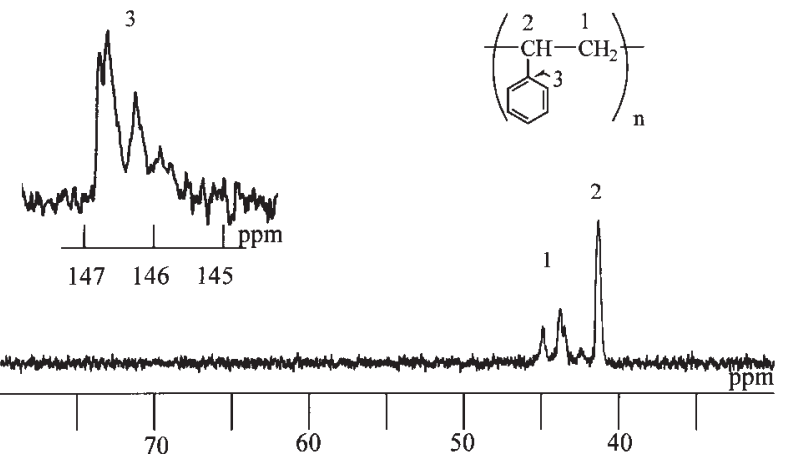

(b)

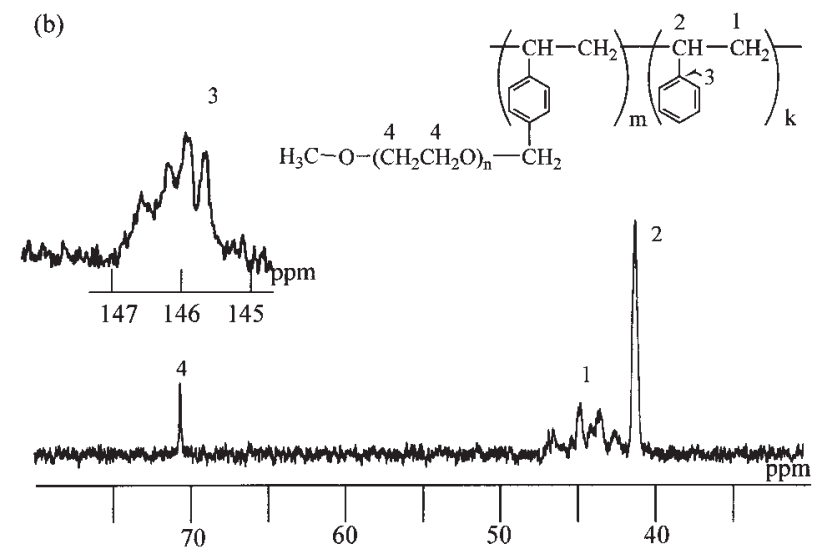

Figure 4. ${ }^{13} \mathrm{C}$ NMR spectra of the polymers obtained from polymerization of St (a) and copolymerization of SEOM and $\mathrm{St}$ (b) with $\mathrm{Ni}$ (acac) $)_{2} / \mathrm{MAO}$ catalyst measured in $o$-dichlorobenzene $/ \mathrm{C}_{6} \mathrm{D}_{6}$ at $120^{\circ} \mathrm{C}$.

and St with $\mathrm{Ni}(\mathrm{acac})_{2} / \mathrm{MAO}$ catalyst.

\section{Tacticity of Graft Copolymer}

The ${ }^{13} \mathrm{C}$ NMR spectrum of the graft copolymer is shown in Figure 4, in which the spectrum of poly $(\mathrm{St})$ synthesized by polymerization of St with $\mathrm{Ni}(\mathrm{acac})_{2} /$ MAO catalyst under similar conditions is also indicated to comparison. The peak based on $\mathrm{C}_{1}$ carbon of the phenyl group as shown in Figure 4 appeared at 145.5 $\mathrm{ppm}$, and it was splitting due to tacticity of St units. ${ }^{33}$ From the peak, triad tacticity of the graft copolymer was estimated to be $25.8 \%$ for $\mathrm{mm}, 46.6 \%$ for $\mathrm{mr}$ and $27.7 \%$ for rr. The mm content of the graft copolymer synthesized by copolymerization of St and SEOM with the $\mathrm{Ni}(\mathrm{acac})_{2} / \mathrm{MAO}$ catalyst was found to be lower than poly(St) by polymerization of St with the $\mathrm{Ni}(\mathrm{acac})_{2} / \mathrm{MAO}$ catalyst (mm: $54.5 \%$, mr: $36.6 \%$, rr: $8.8 \%)$.

\section{Effect of MAO/Ni Mole Ratio}

A synthesis of isotactic polymer of St was reported to depend strongly on the $\mathrm{MAO} / \mathrm{Ni}$ molar ratio in the 
Table II. Copolymerization of SEOM and $\mathrm{St}$ with $\mathrm{Ni}(\mathrm{acac})_{2} /$ MAO catalyst in toluene at $0{ }^{\circ} \mathrm{C}$ for $160 \mathrm{~h}^{\mathrm{a}}$

\begin{tabular}{cccccccc}
\hline $\begin{array}{c}\text { [SEOM] } \\
(\mathrm{g})\end{array}$ & $\begin{array}{c}\text { Yield } \\
(\%)\end{array}$ & $M_{\mathrm{n}} \times 10^{-4}$ & $M_{\mathrm{w}} / M_{\mathrm{n}}$ & $\begin{array}{c}\text { No. of graft } \\
\text { per chain }^{\mathrm{b}}\end{array}$ & \multicolumn{3}{c}{ Tacticity } \\
\cline { 6 - 9 } & & & & $\mathrm{mm}$ & $\mathrm{mr}$ & $\mathrm{rr}$ \\
\hline 0 & 88 & 3.3 & 1.94 & - & 54.5 & 36.6 & 8.8 \\
0.4 & 5.2 & 3.7 & 2.00 & 9.6 & 25.8 & 46.4 & 27.7 \\
0.7 & 7.4 & 4.7 & 1.85 & 16.0 & - & - & - \\
\hline
\end{tabular}

${ }^{\mathrm{a}} \mathrm{SEOM} ; M_{\mathrm{n}}=2.10 \times 10^{3},[\mathrm{St}]=2.6 \mathrm{~mol} / \mathrm{L},\left[\mathrm{Ni}(\mathrm{acac})_{2}\right]=$ $6.8 \times 10^{-4} \mathrm{~mol} / \mathrm{L}, \mathrm{MAO} / \mathrm{Ni}=10^{\mathrm{b}} \mathrm{Calculated}$ from ${ }^{1} \mathrm{H}$ NMR spectrum of the copolymer and the molecular weight.

polymerization of $\mathrm{St}$ with $\mathrm{Ni}(\mathrm{acac})_{2} / \mathrm{MAO}$ catalyst, and low $\mathrm{MAO} / \mathrm{Ni}$ molar ratio was favorable conditions for producing isotactic polymer. ${ }^{17}$ Then, the graft copolymerization of St and SEOM with $\mathrm{Ni}(\mathrm{acac})_{2} /$ $\mathrm{MAO}$ catalyst was conducted at $\mathrm{MAO} / \mathrm{Ni}$ molar ratio of 10. The results are listed in Table II. The mm contents of the graft copolymer did not change. It was reported that an active site for producing isotactic polymer in the polymerization of $\mathrm{St}$ with $\mathrm{Ni}(\mathrm{acac})_{2} / \mathrm{MAO}$ catalyst was not stable. In the graft copolymerization of St and SIPM with $\mathrm{Ni}(\mathrm{acac})_{2} / \mathrm{MAO}$ catalyst, highly isotactic graft copolymer $(\mathrm{mm}=91 \%)$ was synthesized even though the copolymerization conditions of St with SIPM was similar to that of St with SEOM. ${ }^{28}$ Thus, the ethylene oxide units in the SEOM may be related to reduce the $\mathrm{mm}$ contents in the copolymerization of SEOM and St.

\section{CONCLUSIONS}

A graft copolymer consisting of SEOM and St was synthesized from the copolymerization of $\mathrm{St}$ and SEOM with $\mathrm{Ni}(\mathrm{acac})_{2} / \mathrm{MAO}$ catalyst. The number of graft chains in the copolymerization with $\mathrm{Ni}(\mathrm{acac})_{2} / \mathrm{MAO}$ catalyst was controlled by varying the SEOM in comonomer feed. However, the high $\mathrm{mm}$ content of graft copolymer was not synthesized by copolymerization of SEOM and St with $\mathrm{Ni}(\mathrm{acac})_{2} / \mathrm{MAO}$ catalyst.

\section{REFERENCES}

1. K. Ito, Prog. Polym. Sci., 23, 581 (1998).

2. Y. Tsukahara, Y. Ohta, and K. Senoo, Polymer, 36, 3413 (1995).

3. Y. Tsukahara, Kobunshi Ronbunshu, 54, 843 (1997).

4. N. M. Reynolds, J. D. Savage, and S. L. Hsu, Macromolecules, 22, 2869 (1989).
5. Y. Tsukahara, K. Tsutsumi, Y. Yamashita, and S. Shimada, Macromolecules, 23, 5201 (1990).

6. K. Ito, H. Tsuchida, A. Hayashi, T. Kitano, E. Yamada, and T. Matsumoto, Polym. J., 17, 827 (1985).

7. D. Chao, S. Itsuno, and K. Ito, Polym. J., 23, 1045 (1991).

8. M. Maniruzzaman, S. Kawaguchi, and K. Ito, Macromolecules, 33, 1583 (2000).

9. T. C. Chung, L. H. Lu, and R. D. Ding, Macromolecules, 30, 1272 (1997).

10. T. Shiono, Y. Moriki, and K. Soga, Macromol. Symp., 97, 161 (1997).

11. O. Henschke, A. Neubauer, and M. Arnold, Macromolecules, 26, 8097 (1997).

12. K. Endo and K. Senoo, Macromol. Rapid Commun., 19, 563 (1998).

13. K. Endo and K. Senoo, Polym. J., 31, 817 (1999).

14. K. Endo and K. Senoo, Polymer, 40, 5977 (1999).

15. K. Endo and K. Senoo, Polym. Bull., 44, 25 (2000).

16. K. Senoo, K. Endo, S. Murakami, and M. Tosaka, Chem. Lett., 29, 278 (2000).

17. P. Long, A. Grassi, L. Oliva, and P. Ammendola, Makromol. Chem. Phys., 191, 237 (1990).

18. K. Endo and K. Masaki, Kobunshi Ronbunshu, 51, 652 (1994).

19. K. Endo and K. Masaki, Macromol. Rapid Commun., 16, 779 (1995).

20. G. L. Crossetti, C. Bormioli, A. Giarrusso, and L. Porri, Macromol. Rapid Commun., 18, 801 (1997).

21. F. Peruch, H. Gramail, and A. Deffieux, Macromol. Chem. Phys., 199, 2221 (1998).

22. T. J. Deming, B. M. Novak, and J. W. Ziller, J. Am. Chem. Soc., 116, 2366 (1994).

23. R. Taube, H. Windisch, and A. Maiwald, Macromol. Symp., 89, 393 (1995).

24. K. Endo, Y. Uchida, and Y. Matsuda, Macromol. Chem. Phys., 197, 3515 (1996).

25. K. Endo, Y. Uchida, and K. Masaki, Polym. J., 29, 583 (1997).

26. K. Endo, A. Inukai, and T. Otsu, Macromol. Rapid Commun., 15, 893 (1994).

27. F. M. B. Coutinho, M. A. S. Costa, L. F. Montero, and L. C. Maria, Polym. Bull., 38, 303 (1997).

28. K. Endo and K. Senoo, J. Polym. Sci., Part A: Polym. Chem., 38, 1241 (2000).

29. K. Ito, H. Tsuchida, A. Hayashi, T. Kitano, E. Yamada, and T. Matsumoto, Polym. J., 17, 827 (1985).

30. D. Chao, S. Itsuno, and K. Ito, Polym J., 23, 1045 (1991).

31. M. Maniruzzaman, S. Kawaguchi, and K. Ito, Macromolecules, 33, 1583 (2000).

32. K. Endo and T. Sugita, J. Polym. Sci., Part A: Polym. Chem., 42, 2904 (2004).

33. N. Ishihara, T. Seimiya, M. Kuramoto, and M. Uoi, Macromolecules, 19, 2464 (1986). 